\title{
Enprostil and ranitidine in duodenal ulcer healing: double blind comparative trial
}

\author{
KARSTEN LAURITSEN, LAURITS STÆRK LAURSEN, TROELS HAVELUND, \\ PETER BYTZER, LARS B SVENDSEN, JØRGEN RASK-MADSEN
}

\begin{abstract}
One hundred and eighty patients with endoscopically proved duodenal ulcers were allocated at random to double blind treatment with the synthetic dehydroprostaglandin $E_{2}$ enprostil $35 \mu \mathrm{g}$ twice daily or ranitidine $150 \mathrm{mg}$ twice daily for up to six weeks. Patients completed the study if ulcer healing and pain relief had occurred at two or four weeks. A total of 163 patients completed the trial. The duration of treatment was longer in the enprostil group $(\mathbf{p}<0.005)$ and the cumulative healing rates at two, four, and six weeks were $51 \%, 74 \%$, and $85 \%$, respectively. In the ranitidine group the corresponding figures were $65 \%$ $(p<0.04), 89 \%(p<0.02)$, and $99 \%(p<0.002)$. More patients treated with ranitidine reported relief of pain $(p<0.004$ at weeks 5 and 6).
\end{abstract}

The observed superiority of ranitidine $150 \mathrm{mg}$ twice daily over enprostil $35 \mu \mathrm{g}$ twice daily questions the clinical relevance of using so called "cytoprotection" as treatment for duodenal ulcer disease in the short term.

\section{Introduction}

Most clinical trials of histamine $\mathrm{H}_{2}$-receptor antagonists have shown that $20-30 \%$ of duodenal ulcers remain unhealed after four weeks. ${ }^{1}$ Reducing the failure rate is desirable, since unhealed ulcers may cause pain and complications. Synthetic prostaglandin analogues of the $E$ series offer a new approach to the medical treatment of peptic ulcer disease. Prostaglandins are believed to maintain integrity of the gastric mucosa by decreasing secretion of gastric acid, stimulating secretion of mucus and bicarbonate, and modulating mucosal blood flow. ${ }^{3}$ The capacity of prostaglandins to protect the mucosa by mechanisms independent of acid inhibition is termed "cytoprotection." Enprostil is a novel synthetic dehydroprostaglandin $\mathrm{E}_{2}$ which combines antisecretory ${ }^{47}$ with cytoprotective properties, such as to protect the antral mucosa against damage induced by aspirin ${ }^{8}$ even at doses below those required for acid inhibition. Hence it might be expected that enprostil given in antisecretory doses would heal duodenal ulcers rapidly. To test this we have carried out a double blind randomised trial of enprostil ( $35 \mu \mathrm{g}$ twice daily) and ranitidine ( $150 \mathrm{mg}$ twice daily).

\section{Patients and methods}

Outpatients aged 18-80 with at least one endoscopically proved duodenal ulcer (visual loss of substance) 3-30 mm diameter were considered for the study within three days after endoscopy provided that they did not meet any of the criteria for exclusion. These were pyloric stenosis necessitating surgery; bleeding requiring transfusion within the past three days; recent perforation; previous gastric surgery, except for simple closure; concomitant gastric or prepyloric ulcer; pregnancy or lactation; glaucoma; concomitant treatment (for example, with anti-inflammatory analgesics and steroids or tricyclics) or disease (for example, liver or kidney failure) likely to complicate evaluation of the drug; and clinically relevant laboratory abnormalities in predrug screening values (haemoglobin and serum creatinine concentrations; alkaline phosphatase, alanine aminotransferase, and lactic acid dehydrogenase activities). Each patient gave informed consent and the trial was approved by the regional ethics committees.

Patients were randomly assigned to treatment with either enprostil, one 35 $\mu \mathrm{g}$ capsule in the morning and one in the evening, or ranitidine, one $150 \mathrm{mg}$ tablet in the morning and one in the evening. Inactive capsules and tablets identical in appearance with the active ones had been prepared so that all patients received the same number of tablets or capsules. Adjuvant antacid (Novaluzid chewing tablets) was also supplied for pain relief. All other antiulcer treatment was stopped. Patients were given diary cards and recorded use of antacid and intensity of pain during the day and night (pain scored as $0=$ absent, $1=$ mild, $2=$ moderate, $3=$ severe).$^{9}$ An average weekly pain score was calculated separately for day and night in each treatment period as the sum of the score times days or nights with pain, and the "total pain score" was the sum of these scores (that is, an ordinal scale from 0 to 42 ).

Before entry a clinical history and physical examination were undertaken. Patients were seen after two weeks (plus or minus one day) for clinical assessment and endoscopy and those with a healed ulcer-that is, complete epithelialisation of the ulcer site-and relief of pain given repeated laboratory tests and regarded as having completed the study. In other cases treatment was extended to four weeks (plus or minus two days), and if the patient was still not healed or had pain it was continued to a maximum of six weeks (plus or minus two days), when final clinical assessment, endoscopy, and laboratory screening were done. Endoscopy was omitted at four and six weeks if ulcer healing had been seen at the preceding endoscopy. Returned tablets and capsules were counted at each visit and patients later found not to have taken the active drug for three days or more per fortnight regarded as drop outs.

Statistics-In planning the trial we assumed that a difference of $20 \%$ or more in healing rates between the two groups after two weeks of treatment would be clinically meaningful. We calculated that roughly 90 patients were needed in each group to ensure that the risk of overlooking such a difference was less than $20 \% .{ }^{10}$ Statistical methods used were Fisher's exact test, the $\chi^{2}$ test, the Mantel-Haenszel test, the Mann-Whitney test, the two sample $t$ test, and the Wilcoxon matched pairs signed ranks test, as appropriate. Only two tailed tests were used. Values of $p<0.05$ were considered significant. The $95 \%$ confidence limits for differences in healing between the treatment groups were also calculated. ${ }^{10}$

\section{Results}

Between September 1984 and September 1985, 180 consecutive patients entered the trial-160 from centre 1 (Odense) and 20 from centre 2 (Bispebjerg). Ninety were allocated to receive enprostil ( 80 from centre 1) and 90 to receive ranitidine ( 80 from centre 1$)$. The enprostil treatment group was a little older than the ranitidine group but in other respects the groups were comparable (table I). During weeks 1 and 2 five patients in the enprostil group defaulted and two were withdrawn because of diarrhoea. One patient receiving ranitidine was withdrawn because of progression of rheumatoid arthritis. During weeks 3 and 4 one patient receiving enprostil was withdrawn because of increased pain despite ulcer healing and two receiving ranitidine (one with symptoms but healed ulcer) were withdrawn because of rash and bronchial asthma, respectively. During weeks 5 and 6 
three patients in each group were withdrawn: in the enprostil group two were withdrawn because of increased pain and one because of haemorrhagic gastritis requiring a transfusion. All three had healed ulcers. In the ranitidine group one was withdrawn because of lack of symptomatic effect (ulcer healed), one because the ulcer showed signs of recent bleeding, and one because of transient cerebral ischaemia. The cumulative efficacy at week 6 was therefore based on data from 79 patients in the enprostil group and 84 in the ranitidine group who completed the study according to the protocol. The duration of treatment-that is, until ulcer healing and pain relief or classification as a treatment failure at week 6-was two, four, and six weeks

TABLE I-Characteristics of patients in two treatment groups

\begin{tabular}{|c|c|c|c|}
\hline & $\begin{array}{c}\text { Enprostil } \\
\text { group } \\
(\mathrm{n}=90)\end{array}$ & $\begin{array}{c}\text { Ranitidine } \\
\text { group } \\
(\mathbf{n}=90)\end{array}$ & $\mathrm{p}$ Value \\
\hline Sex ratio $(M: F)$ & $63: 27$ & $52: 38$ & $0.058^{\star}$ \\
\hline Mean age in years (range) & $57 \cdot 4(23-78)$ & $52 \cdot 6(22-78)$ & $<0.05 t$ \\
\hline Mean duration of history in years (range) & $11.9(0-55)$ & $11 \cdot 8(0-55)$ & $>0.9 \dagger$ \\
\hline $\begin{array}{l}\text { No with previous ulcer bleeding or } \\
\text { perforation }\end{array}$ & 28 & 23 & $0 \cdot 19^{\star}$ \\
\hline No of smokers & 67 & 68 & $0 \cdot 27^{\star}$ \\
\hline Mean ulcer size in mm (range) & $10 \cdot 4(4-30)$ & $9 \cdot 6(3-25)$ & $>0 \cdot 2 \dagger$ \\
\hline
\end{tabular}

^Fisher's exact test.

†Two sample $t$ test.

for 21,25 , and 33 patients, respectively, in the enprostil group and 37, 31, and 16 patients, respectively, in the ranitidine group $\left(\chi^{2}=10.81 ; \mathrm{df}=2\right.$ $\mathrm{p}=0.0045$ ).

Ulcer healing-Cumulative healing rates were significantly higher in the ranitidine group than in the enprostil group on all study days (table II). For the "intention to treat" cohort the therapeutic gain-that is, the difference in healing rates between the two groups-was further enhanced, because more patients were withdrawn in the enprostil group. Since time to healing is a survival type end point the Mantel-Haenszel test ${ }^{10}$ was used on the intention to treat cohort to cover all three time points; this test provided a more succinct and powerful overall comparison of the two treatments. The result $\left(\chi_{M H}^{2}=10 \cdot 18 ; \mathrm{df}=1 ; p=0 \cdot 0015\right)$ was not explained by the uneven age distribution of the patients in the two treatment groups resulting from the

TABLE II-Healing of duodenal ulcer in patients in two treatment groups (percentages in parentheses)

\begin{tabular}{|c|c|c|c|c|}
\hline $\begin{array}{l}\text { Cumulative } \\
\text { healing rates }\end{array}$ & $\begin{array}{c}\text { Enprostil } \\
\text { group }\end{array}$ & $\begin{array}{l}\text { Ranitidine } \\
\text { group }\end{array}$ & $\begin{array}{c}\% \\
\text { Difference }\end{array}$ & $\mathrm{p}$ Valuef \\
\hline \multicolumn{5}{|c|}{ Patients completing study protocol } \\
\hline $\begin{array}{l}2 \text { Weeks } \\
4 \text { Weeks } \\
6 \text { Weeks }\end{array}$ & $\begin{array}{l}42 / 83(51) \\
61 / 82(74) \\
67 / 79(85)\end{array}$ & $\begin{array}{l}58 / 89(65) \\
77 / 87(89) \\
83 / 84(99)\end{array}$ & $\begin{array}{l}14[15] \\
15[12] \\
14[8]\end{array}$ & $\begin{array}{l}0.038 \\
0.019 \\
0.0015\end{array}$ \\
\hline \multicolumn{5}{|c|}{ Patients "intended to treat" } \\
\hline $\begin{array}{l}2 \text { Weeks } \\
4 \text { Weeks } \\
6 \text { Weeks }\end{array}$ & $\begin{array}{l}42 / 90(47) \\
62 / 90(69) \\
71 / 90(79)\end{array}$ & $\begin{array}{l}58 / 90(64) \\
78 / 90(87) \\
85 / 90(94)\end{array}$ & $\begin{array}{l}17[15] \\
18[12] \\
16[10]\end{array}$ & $\begin{array}{l}0.014 \\
0.0046 \\
0.0029\end{array}$ \\
\hline
\end{tabular}

^Values in square brackets are $95 \%$ confidence limits for differences.

tFisher's exact test.

TABLE III-Healing rates after two weeks according to age, smoking, and ulcer size (percentages in parentheses)

\begin{tabular}{|c|c|c|}
\hline & Enprostil group & Ranitidine group \\
\hline \multicolumn{3}{|l|}{ Age (years): } \\
\hline$\leqslant 57$ & $17 / 34(50)$ & $35 / 56(63)$ \\
\hline$>57$ & $25 / 49(51)$ & $23 / 33(70)$ \\
\hline p Value ${ }^{\star}$ & 0.35 & 0.34 \\
\hline \multicolumn{3}{|l|}{ Smoking: } \\
\hline Smokers & $28 / 62(45)$ & $40 / 67(60)$ \\
\hline Non-smokers & $14 / 21(67)$ & $18 / 22(82)$ \\
\hline p Value & 0.097 & 0.070 \\
\hline \multicolumn{3}{|l|}{ Ulcer size $(\mathrm{mm}) \dagger$ : } \\
\hline$\leqslant 9$ & $30 / 43(70)$ & $35 / 40(88)$ \\
\hline$>9$ & $12 / 40(30)$ & $23 / 47(49)$ \\
\hline p Value & 0.00049 & 0.00021 \\
\hline
\end{tabular}

^Fisher's exact test.

tUlcer size not determined in two patients. random allocation, since retrospective stratification disclosed no influence of age on ulcer healing in either group (table III). In both treatment groups healing rates were lower among smokers, but the differences were not statistically significant. By contrast, size of ulcer seemed to be a strong predictor of healing (table III).

Ulcer pain-The average weekly total pain score was significantly higher in the enprostil group than in the ranitidine group during weeks 5 and 6 $(p=0.03$, Mann-Whitney test) but no differences were found during the first two fortnights. The efficacy of the treatments on pain as assessed by a nominal scale gave a similar result (table IV). There was no significant difference between the treatment groups in consumption of antacid tablets $(\mathrm{p}=0 \cdot 28$, Mann-Whitney test).

TABLE IV-Duration of pain during trial (percentages in parentheses)

\begin{tabular}{lccc}
\hline & \multicolumn{2}{c}{$\begin{array}{c}\text { Cumulative rates in patients } \\
\text { completing study protocol }\end{array}$} & \\
\cline { 2 - 3 } & $\begin{array}{c}\text { Enprostil } \\
\text { group }\end{array}$ & $\begin{array}{c}\text { Ranitidine } \\
\text { group }\end{array}$ & p Value` \\
\hline No pain, weeks 1-2 & $10 / 83(12)$ & $14 / 89(16)$ & $0 \cdot 28$ \\
No pain, weeks 3-4 & $39 / 82(48)$ & $51 / 87(59)$ & $0 \cdot 088$ \\
No pain, weeks 5-6 & $53 / 79(67)$ & $73 / 84(87)$ & $0 \cdot 0031$ \\
& & & \\
\hline
\end{tabular}

^Fisher's exact test.

Side effects and laboratory findings-Diarrhoea-that is, individually increased stool frequency or loose stools, or both-was reported by 12 patients treated with enprostil $(13 \%)$ and in most cases was mild or transient. Among ranitidine treated patients the following complaints were reported: diarrhoea (four patients), constipation (one), dizziness (one), fatigue (two), mild depression (one), rash (one). A few patients were withdrawn because of intercurrent disease, as mentioned above. The Wilcoxon matched pairs signed ranks test showed no significant differences in laboratory screening values before and after the trial in either study group. In several cases a single value fell outside the reference range for the laboratory concerned, but such abnormalities occurred at random in both treatment groups.

\section{Discussion}

These findings show that ranitidine $150 \mathrm{mg}$ twice daily is superior to enprostil $35 \mu \mathrm{g}$ twice daily in accelerating ulcer healing and bringing pain relief. The results are surprising since enprostil $35 \mu \mathrm{g}$ twice daily has been claimed to have antisecretory effects comparable $^{4}$ or superior ${ }^{5}$ to those of cimetidine $600 \mathrm{mg}$ twice daily. The healing rates in the ranitidine group were identical with those observed in our previous study ${ }^{9}$ and comparable to rates reported in other recent trials. ${ }^{11}{ }^{12}$ By contrast, the healing rates at two weeks were lower than those found after treatment with omeprazole, ${ }^{12}{ }^{13} \mathrm{a}$ proton pump inhibitor which has a more pronounced inhibitory effect on acid. ${ }^{14}$

The dose of enprostil used in this study inhibits acid secretion and any therapeutic benefit is explicable by this effect rather than by any cytoprotection which may be achieved at lower doses. ${ }^{8}$ Our results therefore question the relevance of cytoprotective properties of antiulcer medication for duodenal ulcer healing. Similarly, recent controlled trials failed to show benefit of cytoprotective prostaglandins in stopping acute bleeding from erosive or ulcerative lesions in the stomach and duodenum and in preventing rebleeding, though endoscopic improvement was seen in concomitant gastritis or duodenitis. ${ }^{15}{ }^{16}$ Nevertheless, cytoprotective properties may be advantageous in other aspects of peptic ulcer disease, such as in preventing ulcer relapse or promoting healing of gastric or prepyloric ulcers, where the correction of abnormal mucosal defence mechanisms such as deficient adaptive cytoprotection may be more important than suppression of acid secretion. Thus the cytoprotective properties of enprostil in man appear to be more pronounced in the antral than duodenal mucosa, ${ }^{8}$ but a conclusion on clinical relevance must still await controlled trials.

We thank Mrs Rigmor Petersen for secretarial help; the staff of our endoscopy units for their valued support; and Syntex Inc, Palo Alto, California, for supplying the study drugs. 


\section{References}

1 Wormsley KG. Short-term treatment of duodenal ulceration. In: Baron JH, ed. Cimetidine in the 80s. Edinburgh: Churchill Livingstone, 1981:3-8.

2 Colin-Jones DG. Ranitidine in the treatment of peptic ulceration. In: Riley AJ, Salmon PR, eds. Ranitidine: proceedings of an international symposium held in the context of the seventh world congress of gastroenterology. Amsterdam: Excerpta Medica, 1982:16-29.

3 Robert A, Lancaster C, Davis JP, Field SO, Sinha AJW, Thornburgh BA. Cytoprotection by prostaglandin occurs in spite of penetration of absolute ethanol into the gastric mucosa. Gastroenterology 1985;88:328-33.

4 Davis GR, Walsh JH, Santa Ana CA, Morawski SG, Fordtran JS. Effect of cimetidine and enprostil (a Syntex investigational prostaglandin $E_{2}$ ) on gastric acidity and serum gastrin concentrations in normal subjects [Abstract]. Gastroenterology 1984;86:1058.

5 Mahachai V, Walker K, Sevelius H, Thomson ABR. Enprostil, a dehydro-prostaglandin $E_{2}$, has potent antisecretory and antigastrin properties in patients with duodenal ulcer disease [Abstract]. Gastroenterology 1984;86:1171.

6 Santana IA, Sharma BK, Orchard K, Pounder RE. Twenty-four hour intragastric acidity before and during treatment with enprostil [Abstract]. Gut 1985;26:A545.

7 Deakin M, Ramage JK, Paul A, Gray S, Billings J, Williams JG. Effect of enprostil on 24 hour intragastric acidity and nocturnal acid and pepsin output [Abstract]. Gut 1985;26:A545.

8 Cohen MM, Mc(ready DR, Clark L, Sevelius H. Protection against aspirin-induced antral and duodenal damage with enprostil. A double-blind endoscopic study. Gastroenterologv 1985;88: $382-6$.
9 Lauritsen K, Bytzer P, Hansen J, Bekker C, Rask-Madsen J. Comparison of ranitidine and highdose antacid in the treatment of prepyloric or duodenal ulcer. A double-blind controlled trial. dose antacid in the treatment of prep

10 Fleiss JL. Statistical methods for rates and proportions. New York: John Wiley \& Sons, 1981.

11 Ireland A, Colin-Jones DG, Gear P, et al. Ranitidine $150 \mathrm{mg}$ twice daily vs $300 \mathrm{mg}$ nightly in the treatment of duodenal ulcers. Lancet 1984;ii:274-6.

12 Classen M, Dammann HG, Domschke W, et al. Short-duration treatment of duodenal ulcer with omeprazole and ranitidine: results of a multi-centre trial in Germany. Disch Med Wochenschr 1985;110:210-5.

13 Lauritsen K, Rune SJ, Bytzer P, et al. Effect of omeprazole and cimetidine on duodenal ulcer. A double-blind comparative trial. $N$ Engl f Med 1985;312:958-61.

14 Walt RP, Gomes M de FA, Word EC, Logan LH, Pounder RE. Effect of daily oral omeprazole on 24 hour intragastric acidity. Br Med f 1983;287:12-4.

15 Levine BA, Sirinek KR, Gaskill HV. Topical prostaglandin $E_{2}$ in the treatment of acute upper gastrointestinal tract hemorrhage. A prospective, randomized, double-blind study. Arch Surg 1985;120:600-4.

16 Lauritsen K, Laursen LS, Havelund T, Bytzer P, Rask-Madsen J. Controlled trial of arbaprostil in bleeding peptic ulcer. BrMed f 1985;291:1093.

(Accepted 13 February 1986)

\section{SHORT REPORTS}

\section{Cholestatic jaundice caused by ethambutol}

Jaundice is a well recognised adverse reaction in patients receiving antituberculous chemotherapy and is usually ascribed to rifampicin, isoniazid, or pyrazinamide. Ethambutol is thought not to cause any hepatotoxic side effects. We report on a patient who developed jaundice during treatment with ethambutol.

\section{Case report}

A 78 year old woman, a retired pottery worker, presented with a history of weight loss, night sweats, cough, and haemoptysis. Chest $x$ ray films showed simple pneumoconiosis with some recently developed soft shadowing in the right upper lobe. Cultures of sputum samples contained Mycobacterium tuberculosis, which was fully sensitive to first line drugs. She did not have a history of adverse drug reactions or excessive consumption of alcohol, and results of biochemical liver function tests were normal.

She was treated initially with streptomycin $0.5 \mathrm{~g}$ intramuscularly twice weekly, isoniazid $300 \mathrm{mg}$ daily, and ethambutol $750 \mathrm{mg}(15 \mathrm{mg} / \mathrm{kg})$ daily by mouth beginning on 17 November 1983. After two months she developed painless jaundice with pale stools and dark urine. Serum bilirubin was $201 \mu \mathrm{mol} / 1$ $(11.8 \mathrm{mg} / 100 \mathrm{ml})$, alkaline phosphatase $976 \mathrm{U} / \mathrm{l}, \gamma$-glutamyltransferase $616 \mathrm{U} / \mathrm{l}$, and aspartate transaminase $264 \mathrm{U} / \mathrm{l}$. Treatment was stopped on 20 January 1984. Tests for hepatitis B surface antigen, hepatitis A IgM antibodies, cytomegalovirus antibodies, smooth muscle antibodies, and antimitochondrial antibodies and the Paul Bunnell test yielded negative results. Two ultrasound scans showed that the structure of the liver was normal with no evidence of dilatation of the biliary tree; a liver biopsy specimen showed cholestasis.

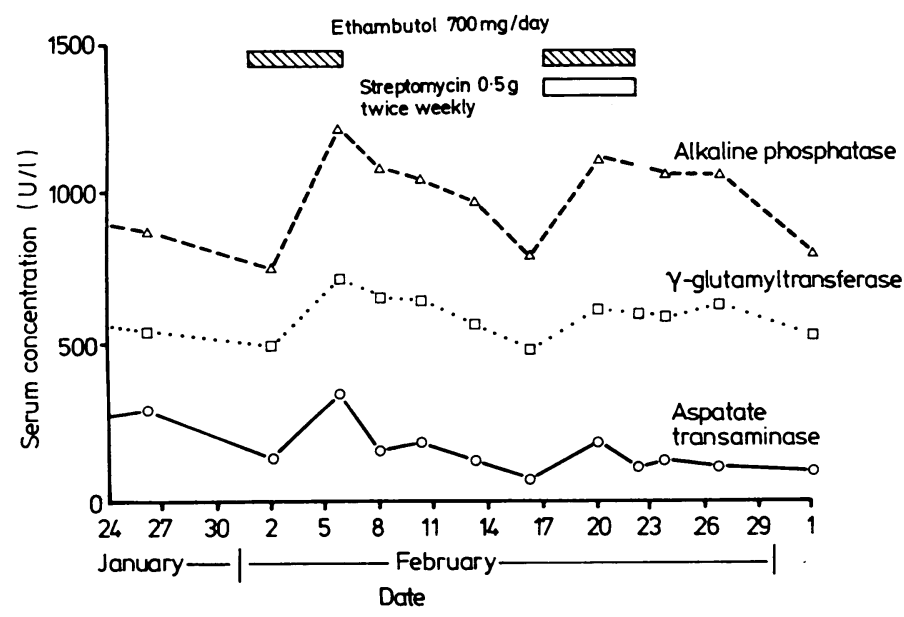

Serial changes in hepatic enzyme activities during treatment with ethambutol.
Her jaundice was thought to be due to isoniazid, and treatment was restarted on 1 February with ethambutol ( $700 \mathrm{mg}$ daily) alone to test whether isoniazid was the offending drug. During six days' treatment the alkaline phosphatase activity increased from $767 \mathrm{UV}$ to $1225 \mathrm{U} / \mathrm{l}$ and aspartate transaminase activity from $144 \mathrm{U} / 1$ to $356 \mathrm{U} / 1$ (figure). Treatment was stopped on 6 February for 11 days, during which time the results of liver function tests improved. On 17 February ethambutol was again started together with streptomycin $0.5 \mathrm{~g}$ twice weekly. Within four days there was a further increase in the alkaline phosphatase activity, from $812 \mathrm{U} / 1$ to $1128 \mathrm{U} / 1$, and in aspartate transaminase activity, from $76 \mathrm{U} / \mathrm{l}$ to $228 \mathrm{U} / 1$ (figure). When the drugs were stopped the results of liver function tests slowly returned to normal. Subsequent treatment with isoniazid and streptomycin was uneventful.

\section{Comment}

Hepatic problems are well described in patients receiving rifampicin, isoniazid, or pyrazinamide and often limit options for treatment, particularly in the elderly. ${ }^{1}$ The risk of jaundice induced by drugs increases with age and the presence of pre-existing liver disease. In our case the initial drug regimen was chosen because of the high risk of hepatotoxicity from rifampicin in the elderly.

Among first line drugs in current use streptomycin is usually considered to be free from hepatotoxic effects while possible hepatotoxicity due to ethambutol is poorly documented. A single case of jaundice during treatment with ethambutol has been noted but not documented. ${ }^{2}$ In other cases jaundice has occurred during treatment with rifampicin, isoniazid, and pyrazinamide and has been considered to have been due to these drugs. ${ }^{3.5}$ The Committee on Safety of Medicines has received one report of hepatitis and one of hepatic cirrhosis during treatment with ethambutol, but the cause of these cases was uncertain. The manufacturers are not aware of any hepatotoxicity thought to be due to ethambutol, but the possibility of such reactions should be considered in patients receiving chemotherapy for tuberculosis.

1 Mackay AD, Cole RB. The problems of tuberculosis in the elderly. $Q \mathcal{f}$ Med 1984;53:497-510.

2 Fandos E, Guallar J. Results obtained with ethambutol in the treatment of chronic pulmonary tuberculosis in medical institutions. Rev Clin Esp 1968;110:319-28.

3 Lees AW, Allan GW, Smith J, et al. Rifampicin plus isoniazid in initial therapy of pulmonary tuberculosis and rifampicin and ethambutol in retreatment cases. Chest 1972;61:579-82

4 Segarra FO, Lorian V, Sherman DS. Ethambutol treatment of tuberculosis in a controlled trial. Scandinavian Joumal of Respiratory Disease 1968;49:202-6.

5 British Thoracic Association. A controlled trial of six months' chemotherapy in pulmonary tuberculosis. Br $\mathcal{F}$ Dis Chest 1981;75:141-53.

(Accepted 8 February 1986)

North Staffordshire Hospital Centre, City General Hospital, Stoke on Tren ST4 6QG

M GULLIFORD, MRCP, medical registrar

A D MACKAY, MD, MRCP, senior registrar in general and thoracic medicine

K PROWSE, MD, FRCP, consultant physician

Correspondence to: Dr K Prowse, Department of Respiratory Physiology, City General Hospital, Stoke on Trent ST4 6QG. 